УДК 346.1

DOI: 10.26456/vtpravo/2021.3.013

\title{
О ПЕРСПЕКТИВАХ ПРАВОВОГО РЕГУЛИРОВАНИЯ ИСПОЛЬЗОВАНИЯ ИСКУССТВЕННОГО ИНТЕЛЛЕКТА В РОССИЙСКОЙ ФЕДЕРАЦИИ
}

\author{
А.Н. Сухарев \\ ФГБОУ ВО «Тверской государственный университет», г. Тверь
}

В статье рассмотрена сущность и содержание искусственного интеллекта, необходимость правового регулирования использования искусственного интеллекта в Российской Федерации. Представлены концептуальные положения правовых норм проекта федерального закона о правовом регулировании искусственного интеллекта в Российской Федерации.

Ключевые слова: технологии искусственного интеллекта, слабый искусственный интеллект, сильный семантические сети, машинное обучение, торговые роботы, риск, финансовые технологии.

В современном мире стремительно происходит внедрение искусственного интеллекта во многие сфере общественной жизни. Все больше он начинает использоваться в финансовой сфере, здравоохранении, выявлении угроз личности, обществу и государству и др. Будущие технологии невозможны без использования искусственного интеллекта, а сам он становится главным драйвером роста мировой экономики.

Под искусственным интеллектом принято понимать способность специально создаваемых систем имитировать творческую деятельность человека, обладающих способностью к поиску нового. В «Национальной стратегии развития искусственного интеллекта на период до 2030 года», которая была утверждена указом Президента Российской Федерации от 10 октября 2019 г., под искусственным интеллектом понимается комплекс технологических решений, позволяющий имитировать когнитивные функции человека (включая самообучение и поиск решений без заранее заданного алгоритма) и получать при выполнении конкретных задач результаты, сопоставимые с результатами интеллектуальной деятельности человека. В той же Национальной стратегии под технологиями искусственного интеллекта понимаются технологии, основанные на использовании искусственного интеллекта, включая компьютерное зрение, обработку естественного языка, распознавание и синтез речи, интеллектуальную поддержку принятия решений и перспективные методы искусственного интеллекта [1].

В философии принято выделять два уровня искусственного интеллекта - сильного и слабого. Под сильным искусственным интеллектом понимается возможность создания технических систем 
(прежде всего компьютеров), которые бы получили способность к собственному мышлению и обрели сознание. В этом плане теория сильного искусственного интеллекта требует конструирования искусственного сознания. Сегодня развитие технологий не ведет к появлению искусственного сознания, оно остается некоей тайной, выходящей за пределы науки. Поэтому в науке и технике под искусственным интеллектом понимается слабый искусственный интеллект, который не предполагает появления искусственного сознания и собственной внутренней воли.

Искусственный интеллект в современном понимании основан на использовании семантических сетей и машинного обучения. Именно такие методы обработки информации в настоящее время позволяют имитировать творческую деятельность человека. С помощью данных методов можно осуществлять процедуры самообучения искусственных систем без традиционного алгоритмического программирования. Вместе с тем, иногда искусственным интеллектом могут называть и продукт сложного алгоритмического программирования. На основании этого целесообразно разграничить два класса технологий в зависимости от их использования. Под искусственным интеллектом в узком смысле следует понимать технологии, основанные на использовании семантических сетей и машинного обучения, а в широком смысле, в том числе и продукты глубокого алгоритмического программирования. В настоящей статье, автор под искусственным интеллектом будет понимать его в узком смысле.

Центральной проблемой в использовании искусственного интеллекта является невозможность логически обосновать, как он пришел к тому или иному выводу, а тем самым оценить его верность. Вероятно, это то, что должно быть предметом совершенствования в работе искусственного интеллекта, если вообще данная проблема имеет решение. Такой недостаток искусственного интеллекта не позволяет полностью ему доверять и поручить бесконтрольное решение интеллектуальных проблем. Например, в конкурсе красоты в США искусственный интеллект может отдавать предпочтение, лицам европеоидной расы, дискредитируя остальные. Такое решение искусственного интеллекта является отражением неявной дискриминации в обществе определенных слоев населения, что собственно и выявил искусственный интеллект. Это может свидетельствовать о том, что принимаемые результаты решений искусственного интеллекта должны соответствовать этическим стандартам и их следует урегулировать нормами права.

В научной литературе особое внимание уделяется рассмотрению рисков использования технологий искусственного интеллекта $[4$, с. $116-$ $119 ; 6$, с. 267-272; 8, с. 320-335]. Эти риски многообразны и в себя включают социальные, экономические, технические, правовые, 
политические и проч. Технологии с использованием искусственного интеллекта должны быть технически безопасными, не позволять нарушать законодательство, права и свободы граждан, обеспечивать поддержание национальной безопасности и проч.

Насколько вообще целесообразно осуществлять специальное нормативное правовое регулирование использования искусственного интеллекта? Существующее законодательство общими нормами потенциально способно регулировать правоотношения в области использования искусственного интеллекта. Однако принятие специальных норм конкретизирует часто возникающие проблемы защиты прав в области использования искусственного интеллекта. Это также позволит сформировать единую практику судов по сходным вопросам и сократить время разбирательства по данным делам в судах.

Использование искусственного интеллекта в области создания музыкальных и прочих творческих произведений потребует внесения соответствующих изменений в законодательство об авторских правах. Дискуссионным является вопрос о том, кому принадлежит авторское право на музыку сгенерированную искусственным интеллектом. С одной стороны, авторское право могло бы быть признано за лицом, создавшим интеллектуальную систему, которая сгенерировала музыку. Однако проблема в том, что такая система может за день сгенерировать несколько миллионов треков, а за год - уже миллиарды. Учитывая, что в мире таких создателей интеллектуальных систем может быть исчисляться тысячами, а в будущем и миллионами человек, то созданные ими интеллектуальные системы смогут сгенерировать триллионы и квадриллионы музыкальных треков, некоторые из которых могут просто случайно совпасть. Каков должен быть в этом случае механизм защиты авторских прав? Понятно, что он должен быть изменен.

Сегодня в юридической науке все больше появляется исследований по проблемам правового регулирования искусственного интеллекта, посвященного необходимости такого регулирования в Российской Федерации и тех подходах, которые формируются за рубежом [3, с. 256263; 5, с. 79-82; 7, с. 89-91]. Ученые и специалисты высказывают различные точки зрения по разным аспектам такого регулирования, а также вообще о его целесообразности. В 2020 г. Правительство РФ утвердило «Концепцию развития регулирования отношений в сфере технологий искусственного интеллекта и робототехники на период до 2024 г.» [2], в которой определены цели и задачи регулирования отношений в сфере технологий искусственного интеллекта, принципы и особенности такого регулирования. Концепция должна стать основой для разработки нормативного правового регулирования в сфере использования технологий искусственного интеллекта в Российской Федерации. В частности определена необходимость оценки рисков использования таких технологий и их воздействия на права человека, на 
общество и экономику. В концепции указано, что регулированию подлежат те общественные отношения в сфере использования технологий искусственного интеллекта, которые могут нанести реальный ущерб лицам, обществу и государству.

По мнению автора, уже сегодня необходима разработка и принятие федерального закона, который бы регулировал общественные отношения в области применения искусственного интеллекта. В нем, прежде всего, следует обозначить принципы использования искусственного интеллекта. Принципы являются исходными подходами к правовому регулированию общественных отношений. Установление принципов позволит сформировать системный подход к дальнейшему развитию нормативного правового регулирования использования искусственного интеллекта, а также разрешения гражданско-правовых споров в данной области, руководствуясь базовыми правовыми подходами.

Данными принципами следует считать:

Принцип уважения прав личности. Разработка и внедрение технологий искусственного интеллекта должны быть совместимы с основными правами, закрепленными в Конституции РФ и иных федеральных законах;

Принцип недискриминации. Принцип исходит из предотвращения возникновения любой дискриминации между отдельными лицами или группами лиц;

Принцип качества и безопасности использования технологий искусственного интеллекта. Принцип предполагает, что должны использоваться сертифицированные технологии, оцененные с позиции экономической и технической безопасности;

Принцип прозрачности, беспристрастности и справедливости. В технологиях искусственного интеллекта должны использоваться доступные и понятные методы обработки данных и обеспечен доступ внешнего аудита;

Принцип «под контролем пользователя». Пользователи технологий искусственного интеллекта должны быть информированными участниками их функционирования и обладает максимально допустимой полной информации о рисках использования таких технологий.

В федеральном законе необходимо закрепить следующие базовые нормы.

1. Норму о том, что технологии искусственного интеллекта не должны нарушать права человека. Лица, разработавшие или использующие технологии искусственного интеллекта при предоставлении услуг должны нести ответственность за их безопасность. Смысл таких установлений состоит в определении приоритета соблюдения прав человека при использовании технологий искусственного интеллекта. Никакие эффективные технологии искусственного интеллекта не должны нарушать права человека. 
2. Норму о достоверности финансово-экономических расчетов или иных аналитических выводов, получаемые с использованием технологий искусственного интеллекта. Необходимо определить что такие расчеты или иные аналитические выводы не могут являться безусловным доказательством в суде. Также не должно допускаться безусловного применения доказательств в суде, полученных с помощью систем искусственного интеллекта. Стороны могут не соглашаться с результатами, полученными с помощью систем искусственного интеллекта и требовать представления логических доказательств и расчетов, которые можно объективно проверить.

3. Норма о защите персональных данных. Технологии искусственного интеллекта должны обеспечивать защиту персональных данных. Ответственность за раскрытие персональных данных должен нести разработчик технологии искусственного интеллекта, если не будет доказана недобросовестность третьих лиц. Это определит необходимость создания таких технологий искусственного интеллекта, которые не позволят раскрыть персональные данные. Для разработчиков таких технологий это должно служить одним из важнейших правовых ограничений.

4. Норму об удаленной идентификации. Риск неверной идентификации лица должно нести лицо, предлагающее финансовые услуги с использованием удаленной технологии, если не будет доказано недобросовестное поведение лица, вместо которого было идентифицировано другое лицо. Эта норма определит, какая сторона будет нести риск неверной идентификации лиц. Данная норма является востребованной для разрешения гражданско-правовых споров неверной идентификации, устанавливая презумпцию добросовестности потребителей таких услуг.

5. Норму о подконтрольности технологий и систем искусственного интеллекта. Разработчики технологий и систем искусственного интеллекта должны гарантировать подконтрольность таких технологий человеку. Разработчики должны создавать такие технологии и системы искусственного интеллекта, которые не выходили бы из под контроля со стороны человека. Данное требование служит основой для снижения риска использования технологий и систем искусственного интеллекта.

6. Норму о требовании алгоритмической прозрачности. Принятие решений системами искусственного интеллекта должно в максимальной степени иметь логическое объяснение (алгоритмическую прозрачность). Лица, в отношении которых решения принимаются системами искусственного интеллекта должны иметь право на логическое и объективное объяснение таких решений. Требование алгоритмической прозрачности позволяет оценить внутреннюю логику принятия решения системой искусственного интеллекта и позволяет не допустить нарушения прав человека. 
7. Норму о запрете на использование технологий искусственного интеллекта с целью осуществления нелегальной деятельности и финансирования терроризма. Данная норма должна устанавливать прямой запрет на создание технологий искусственного интеллекта, целью которых является осуществление нелегальной деятельности и финансирования терроризма. Это означает, что под запретом должно стать уже само создание «орудия» совершения соответствующих видов преступления.

8. Норму о запрете использования технологий искусственного интеллекта с целью дискриминации. Дискриминация может носить различный характер, включая дискриминация по полу, возрасту, национальности, профессии и проч. Дискриминации преследует целью максимизацию прибыли финансовыми институтами.

9. Норму о недопустимости противоправной манипуляции поведением человека. Использование технологий искусственного интеллекта может приводить к заданному поведению человека с использованием технологий социальной инженерии (манипулирование поведением человека). Норма должна устанавливать прямой запрет противоправной манипуляцией поведением человека. Противоправное поведение связано с обманом, введением в заблуждении, в результате чего человек не может объективно оценить для себя необходимость тех или иных услуг.

10. Норму о недопустимости преднамеренного нарушения правовых норм при разработке систем искусственного интеллекта. Разработчики технологий и систем искусственного интеллекта обязаны оценивать риски использования таких систем. Риски использования технологий и систем искусственного интеллекта должны быть раскрыты пользователям таких систем.

11. Норму об обязательном страховании гражданской ответственности использования технологий и систем искусственного интеллекта. Следует установить, что Правительство Российской Федерации может устанавливать требования для обязательного страхования гражданской ответственности использования технологий и систем искусственного интеллекта. Норма направлена на защиту гражданской ответственности использования технологий и систем искусственного интеллекта.

12. Норму о правовом регулировании использования торговых роботов на основе искусственного интеллекта. Сегодня на фондовом рынке России и за рубежом более половины сделок по купле и продажи ценных бумаг совершают торговые роботы. Необходимо определить, что торговые роботы на основе искусственного интеллекта являются технологическими решениями, основанными на использовании машинного обучения и нейронных сетей и обладают способностью к самообучению. Установить, что риск использования торговых роботов на 
основе искусственного интеллекта должен нести их пользователь. Брокеры, при предложении услуг торгового робота на основе искусственного интеллекта, должны информировать о рисках их использования и об отсутствии гарантии получения дохода или сохранения капитала в будущем при наличии такого факта в прошлом.

13. Норму об особенностях установления стоимости услуг использования торгового робота на основе искусственного интеллекта. Эта стоимость не может быть установлена в виде процента от прибыли, которую получает от его использования участник финансового рынка. Если бы стоимость робота формировалась бы как доля от прибыли, то это вводило бы в заблуждение участников финансового рынка о действительной прибыльности торгового робота с учетом взлета и падения цен на акции.

14. Норму об обязательности использования пилотного режима. Разработанные новые технологии и системы искусственного интеллекта до их широкого внедрения должны эксплуатироваться в пилотном (ограниченном) режиме. Установить, что длительность пилотного режима и степень ограничения использования определятся разработчиками искусственного интеллекта самостоятельно исходя из необходимости выявления основных рисков и несанкционированных последствий использования.

Итак, подытоживая вышеизложенное можно сделать вывод о том, что развитие технологий искусственного интеллекта требует принятия специальных правовых норм его использования в целях эффективной защиты прав граждан. В специальном законодательстве, регулирующем использование искусственного интеллекта, необходимо определить нормы о защите персональных данных, об удаленной идентификации, о подконтрольности технологий и систем искусственного интеллекта, о требовании к алгоритмической прозрачности, о запрете на использование технологий искусственного интеллекта с целью осуществления нелегальной деятельности и финансирования терроризма, о запрете использования технологий искусственного интеллекта с целью дискриминации, о недопустимости противоправной манипуляции поведением человека, о недопустимости преднамеренного нарушения правовых норм при разработке систем искусственного интеллекта, об обязательном страховании гражданской ответственности использования технологий и систем искусственного интеллекта, о правовом регулировании использования торговых роботов на основе искусственного интеллекта, об особенностях установления стоимости услуг использования торгового робота на основе искусственного интеллекта, об обязательности использования пилотного режима. 


\section{Список литературы}

1. Национальная стратегия развития искусственного интеллекта на период до 2030 года, утв. Указом Президента РФ от 10.10.2019 г № 490 «О развитии искусственного интеллекта в Российской Федерации» // СПС «КонсультантПлюс».

2. Концепция развития регулирования отношений в сфере технологий искусственного интеллекта и робототехники на период до 2024 г.», утв. Распоряжением Правительства РФ от 19 августа 2020 г. № 2129-р // СПС «КонсультантПлюс».

3. Архипова А.С. Правовое регулирование использования технологии искусственного интеллекта в сфере финансовых технологий // Право и бизнес: правовое пространство для развития бизнеса в России / отв. ред. С.Д. Мигилевский и др. М., 2020.

4. Гримашевич О.Н. Риски и возможности развития цифровой экономики // Наука и общество. 2020. № 2 (37). С. 116-119.

5. Никифоров С.В. Правовое регулирование и оформление правосубъектности искусственного интеллекта в российском и международном праве // Пробелы в российском законодательстве. 2020. № 1. С. 79-82.

6. Никишова М.И. Обзор рисков применения искусственного интеллекта в управлении // Шаг в будущее: искусственный интеллект и цифровая экономика. Революция в управлении: новая цифровая экономика или новый мир машин: материалы II Международного научного форума / под общ. ред. П.В. Терелянского. М.: Издательский дом ГУУ, 2018. 478 с.

7. Серобян Г.А. Правовое регулирование систем искусственного интеллекта: за или против // Право и государство: теория и практика. 2019. № 10. C. 89-91.

8. Щитова А.А. Риски применения технологий искусственного интеллекта и пути их преодоления // Актуальные проблемы развития юридической науки в условиях правовой интеграции. Монография. К 90-летию Университета имени О.Е. Кутафина (МГЮА) / под общ. ред. В.В. Блажеева, М.А. Егоровой. М., 2021. $420 \mathrm{c}$.

\section{Об авторе:}

СУХАРЕВ Александр Николаевич - доктор экономических наук, профессор кафедры конституционного, административного и таможенного права ФГБОУ «Тверской государственный университет» (170100, г. Тверь, ул. Желябова, 33), SPIN-код: 2416-1054, mail: su500005@ yandex.ru. 
Вестник Тверского государственного университета. Серия «Право». 2021. № 3 (67)

ON THE PROSPECTS OF LEGAL REGULATION OF THE USE OF ARTIFICIAL INTELLIGENCE IN THE RUSSIAN FEDERATION

\section{A.N. Sukharev}

Tver State University

The article discusses the essence and content of artificial intelligence, the need for legal regulation of the use of artificial intelligence in the Russian Federation. The conceptual provisions of the legal norms of the draft federal law on the legal regulation of artificial intelligence in the Russian Federation are presented.

Keywords: artificial intelligence technologies, weak artificial intelligence, strong semantic networks, machine learning, trading robots, risk, financial technology

\section{About author:}

SUCHAREV Alexander - Doctor of Economics, professor of constitutional, administrative and customs law Tver State University (170100, Tver, Zhelyabova street, 33), SPIN-code: 2416-1054, e-mail: su500005@yandex.ru

Сухарев А.Н. О перспективах правового регулирования использования искусственного интеллекта в Российской Федерации // Вестник ТвГУ. Серия: Право. 2021. № 3 (67). С. 13-21. 